\title{
Origen de las escuelas normales: una breve mirada a las escuelas normales brasileñas y colombianas
}

\author{
Origin of the normal schools: \\ a brief view to brazilian and colombian normal schools
}

\author{
Nilce Vieira Campos FERREIRA ${ }^{1}$ \\ Yesica Paola Montes GELES²
}

\begin{abstract}
Resumen
Establecemos un diálogo sobre la creación de las escuelas normales brasileńas y las colombianas. El texto prioriza la escritura de la historia de los sujetos comunes, el análisis de los datos históricos de instituciones escolares y de la historia de las escuelas normales brasileñas mato-grossenses y colombianas. Identificamos que las escuelas normales surgen de la búsqueda por la formación de profesores para actuar en los espacios escolares. Los profesores, considerados históricamente educadores de la patria, debian cumplir la normatividad de los Gobiernos; sin embargo, los fines educativos variaban con los cambios políticos y económicos de cada país.
\end{abstract}

Palavras-clave: Escuelas Normales. Instituciones Escolares. Brasil. Colômbia.
Abstract

This article focused on the creation of brazilian and colombian normal schools. It prioritized the writing of the history of the common subjects, the analysis of schools' historical data, and the history of Brazilian mato-grossenses and Colombian Normal schools. Also, we cited authors who refer to the history of education, history of schools and teacher training. We identified that Normal schools emerge from the search of teacher training, which empowers educators to work in learning spaces. Teachers, who are historically considered homeland's educators, should comply with their governments' regulations. However, we found out that teaching purposes varied depending on the political and economic changes of each country.

Keywords: Normal Schools. School institutions. Brazil. Colombia.

1 Doutora em Educação pela Universidade de Uberlândia (UFU). Professora do Programa de Pós-Graduação em Educação da Universidade de Mato Grosso (UFMT/Cuiabá). End.: Av. Fernando Corrêa da Costa, no 2367, Bairro Boa Esperança, Cuiabá, Mato Grosso, CEP: 78060-900, tel.: (65) 3365-8369. Email: $<$ nilcevieiraufmt@gmail.com>.

2 Magíster en educación de la Universidade Federal de Mato Grosso (UFMT). Profesora de la Corporación Universitaria del Caribe (CECAR, Sincelejo). Adscrita al grupo de investigación Educación, universidad y sociedade de la Universidad de Cartagena. Carrera Troncal de Occidente-Km 1 Vía Corozal SincelejoColombia, tel: 3145248816. Email: <yesica.montes.g55@gmail.com>.

R. Educ. Públ.

Cuiabá

v. 27

n. $65 / 1$

p. $487-506$ maio/ago. 2018 


\section{Introducción}

Cuando hablamos de estudiar establecimientos educativos desde la Historia de la Educación entendemos que para analizarlos debemos tener en cuenta el contexto particular de la institución objeto de estudio y a la vez, el contexto social, político, económico y cultural que la rodea. Caso particular de las instituciones educativas para formar maestros, además de lo anterior, es pertinente estudiar la realidad de los profesores en la sociedad.

Es nuestro deber, para este estudio, trazar un breve relato sobre el origen de las escuelas normales como formadoras de profesores para la enseñanza primaria, el cual se encuentra inserido, a nivel mundial, entre la búsqueda de una nueva forma de educación y la formación de maestros como demanda escolar. En el siglo XVI, en Madrid, Francia y Alemania, como lo expone Santiago Reyes Hernández (1960), indicios de un interés por educar profesores.

Las escuelas normales como instituciones formadoras de profesores a lo largo de la historia merecen un estudio desde la historia de la educación. Este artículo pretende evidenciar como fueron creadas estas escuelas para visibilizar el papel de las mismas en la sociedad. De igual forma, permite reconocer las formas como los profesores, siendo considerados históricamente educadores de la patria, fueron formados para tal fin y cómo estos fines educativos variaban con los cambios políticos y económicos de cada país.

Estudios que posibilitan el análisis de las escuelas normales, desde su surgimiento en Europa como su evolución en América Latina y los cambios que en ellas se presentaron, ayudan a la construcción de la memoria histórica de las escuelas normales. Así mismo, al rescate de la memoria histórica de los profesores y su formación en estos establecimientos escolares.

En esta línea de ideas, es relevante resaltar a través del análisis de documentos históricos la trayectoria de las escuelas normales. Por lo tanto, este artículo se fundamenta en el análisis documentos históricos hallados en los archivos públicos de la ciudad de Cartagena, de la ciudad de Bogotá e de los archivos públicos de la ciudad de Cuiabá en el Brasil. Estos son confrontados con los escritos historiográficos existentes sobre las escuelas normales a nivel mundial y nacional y el análisis documentos históricos hallados en Brazilian Government Documents disponíveis em Center for Research Libraries. ${ }^{3}$

El texto a presentar de divide en dos momentos. El primero de ellos, trae un análisis general del surgimiento de las escuelas normales, empezando desde

Disponível em: <http://www-apps.crl.edu/brazil>. 
Europa hasta llegar a Brasil y Colombia. El segundo momento, se centra en la creación de las escuelas normales brasilenas y colombianas.

\section{Las Escuelas Normales en Europa y Brasil}

Para Humberto Quiceno (1996) y para Hernández (1960) aunque se asume que el primer espacio escolar para educar maestros fue creado por Juan Bautista La Salle, ya existían otros campos de formación con los mismos principios. Agustín Escolano Benito (1982) explica que la Revolución Francesa, en la cual se crea un sistema escolar laico, los países europeos se preocuparon por crear un sistema escolar extenso y modernizado, lo que exigía al mismo tiempo la conformación de un cuerpo docente formado en instituciones pedagógicas para atender la demanda de profesores par actuar en las escuelas, surgiendo, evidentemente, la necesidad de crear escuelas formadoras de maestros.

El take off de la escolarización originó fuertes demandas de maestros, que no podían ser satisfechas con los viejos sistemas de aprendizaje y habilitación corporativista, insuficientes tanto por los criterios profesionales reductivistas como por los métodos empíricos de formación que empleaban. El establecimiento de un sistema escolar extenso y modernizado exigía al mismo tiempo la creación de un cuerpo docente formado en instituciones pedagógicas ad hoc, promovidas y controladas por el propio Estado. Estos son, pues, los condicionantes que explican la génesis y proliferación de las escuelas normales a lo largo del siglo XIX. (BENITO, 1982, p. 55).

Esta necesidad de maestros para las escuelas primarias le dio inicio a la creación de las primeras escuelas normales. En varios países se oficializó la formación de maestros con el objetivo de suplir los propósitos del sistema escolar. Según Benito (1982) la primera Escuela Normal fue creada en Alemania en el año 1732 y a partir de allí, se comienzan a implementar en casi todo el territorio alemán.

En 1794 fue creada la primera escuela normal en Francia para "[...] formar futuros profesores en el arte de enseñar y con la vocación de servir con norma y regla de las que se crearan después" (BENITO, 1982, p. 56). Otros países como Espańa también implementaron sus escuelas normales a a partir de 1834, Argentina en 1869 y Perú en $1822^{4}$.

Ver al respecto: BENITO (1982); ALLIUAUD (1993); ORTIZ (2004). 
Las escuelas normales latinoamericanas tuvieron una influencia directa de las escuelas normales europeas, de las cuales adoptaron sus métodos pedagógicos, considerándolos como pilares de la educación. Claro es, que las escuelas normales en América Latina presentaron una historia particular articulada con los cambios históricos vividos en cada país, lo que acabó por generar una serie de reformas a lo largo de los años y muchas dificultades para que esta modalidad formativa alcanzara de forma igualitaria a la población.

La historia de las escuelas normales en latinoamérica en el siglo XIX avanzó a paso lento intentando cumplir con las necesidades educativas particulares, inseridas en un ambiente político de constantes cambios. En palabras de Hernández (1960, p. 43) "[...] la debilidad del movimiento normalista latinoamericano en el siglo XIX se debe en cambio, a su agitada historia política."

Países latinos como Brasil y Colombia poseen una historia de las escuelas normales marcada en el siglo XIX. Brasil creó la primera escuela normal en Niterói en Rio de Janeiro en el año de 1835 orientada bajo la influencia de las escuelas europeas y el método lancasteriano 5 . Sin embargo, en palabras de Angela Schaffrath (2008), aunque no se puede negar la incidencia extranjera, se hace necesario entender las políticas brasileras de la época que estructuraron la educación. Esta institución instaurada en la época imperial, según la autora, debía educar a los ciudadanos bajo valores morales considerados necesarios para el avance de la provincia en la época.

A estos hombres fue dada la organización de una escuela normal donde pudieran ser formados los profesores de aquella provincia. Lo que se comprende es que en el Estado que se organizaba, el profesor debería funcionar más como un agente diseminador de una mentalidad moralizarantes que como un difusor de conocimiento. Prueba de ello, es la asistencia de mantener y establecer criterios de selección para el profesorado, donde de ser admitido, el candidato debería estar antes probado de buenas conductas morales y no propiamente presentar preparación intelectual. (SCHAFFRATH, 2008, p. 150).

5 El método lancasteriano fue implementado por primera vez en Inglaterra. Según Francisco Sanabria Múnevar (2010) el método lancasteriano o de enseńanza mutua imitaba la organización de las fábricas de textiles; "[...] se trataba de un gran salón, con un gran número de bancos dispuestos en filas; en el recinto se reunían un maestro, ubicado al frente, y los alumnos, ubicados en las filas. En cada una de las filas, en el extremo, se ubicaba un monitor. El maestro daba la lección únicamente a los monitores, y éstos se la repetían a los demás estudiantes que estaban ubicados en sus respectivas filas [...]" (MÚNEVAR, 2010, p. 52). Ver al respecto: MÚNEVAR, (2010). 
En las primeras escuelas normales de Brasil se formaba un magisterio masculino orientado, como lo muestra la cita anterior, hacia la formación de un buen ciudadano, educado a través de los valores y la moral, lo cual implicaba de forma directa poseer docentes que cumplieran la mismas condiciones. En ese primer momento no existían escuelas normales para la formación de profesoras primarias.

Solamente a partir del ańo 1870 tanto en Brasil como en Colombia se comenzó a pensar en crear escuelas normales para mujeres. En Brasil, según June Edith Hahner (1981), en São Paulo e Rio de Janeiro fueron establecidas sesiones para las mujeres en las escuelas normales. Sin embargo, "[...] las escuelas cerraron y sólo se reabrieron en 1880, después de la Reforma Leôncio de Carvalho, como escuelas mixtas" (HAHNER, 1981, p. 470). En Colombia, las escuelas normales femeninas surgen en el año de 1874 con la proclamación del Decreto $\mathrm{n}^{\circ} 356 \mathrm{de}$ 27 de agosto. No obstante, existía, según Miryam Osorio (2005), desde 1872 en Bogotá, capital del país, una escuela normal para mujeres llamada Escuela Normal de Institutoras de Cundinamarca, la cual "[...] fue el modelo paras las demás escuelas femeninas del país. Allí se formaron las directoras y profesoras para las escuelas normales de los Estados" (OSORIO, 2002, p. 14).

\section{Las Escuelas Normales Mato-Grossenses Brasilenas}

Las escuelas normales mato-grossenses en los últimos ańos del siglo XIX se encontraban a la deriva. Las pocas personas que se dedicaban a la instrucción primaria, en su mayoría no poseían formación específica para actuar como profesores.

La primera Escuela Normal en Mato Grosso fue establecida por la Ley Provincial n. 8 del 5 de mayo de 1837. La Ley n. 8 estableció en su artículo $5^{\circ}$ que “[...] además de las Escuelas de los artículos precedentes el Gobierno establecerá cuanto antes una Escuela Normal para la Instrucción primaria del primer, y segundo año escolar, por el método expedido, y que mejor pueda corresponder a sus fines" (MATTO GROSSO, 1837). Con todo, la primera Escuela Normal de Mato Grosso solamente fue instalada en 1840, en el gobierno del Presidente Cônego José da Silva Guimarães (1840-1843).

La primera Escuela Normal de Cuiabá había sido instalada em 1840; no obstante, cuatro años después fue cerrada en el gobierno del Teniente-Coronel Ricardo José Gomes Jardim (1844-1847), el 9 de noviembre de 1844. Las razones por las que la escuela dejó de funcionar fueron: a) en el estado no había profesores que pudieran formar a los y a las estudiantes normalistas; b) no existía un espacio 
físico adecuado para el funcionamento de la escuela; c) no eran destinados recursos provinciales suficientes para el mantenimiento de la escuela normal mato-grossense. En su discurso dirigido a la Asamblea Legislativa de Mato Grosso Zefirino Pimentel Moreira Freire (1844) resaltó la situación vivida en el estado.

[...] para que de estas escuelas se pueda obtener todas las ventajas que se desean, forzoso es tener todo el escrúpulo en la buena escogencia de los maestros de instrucción pública, que tengan suficiente conocimiento, buenas costumbres, y asiduidad al trabajo, será difícil encontrar individuos com estas características, que se quieran encargar de un ministerio espinoso, con tan exigente orden, pero de alguna forma hay que vencer esa dificultad: aumentar la exigência y aunque hayan pocos, mejor estos escogidos a través de los exámenes de muchos sin habilidades necessarias para el desempeño de sus deberes. (FREIRE, 1844, p, 6-7).

Freire (1844), en aquel discurso resaltó la dificultad de encontrar profesionales capacitados para ejercer la función de professoras/professores primarios. La preocupación del Presidente de la provincia se dirigia hacia la creación de estatutos en los cuales los docentes pudieran ser controlados y que hubiese una persona nombrada para fiscalizar los trabajos, adelantos y avances de las escuelas. El Presidente mencionó que la Ley Provincial n. 8 del 5 de mayo de 1837 había prevenido algunos abusos; sin embargo, la actual inercia en la que se encontraba la provincia y el "[...] sistema de comtemplación deja todo en el mismo estado o peor" (FREIRE, 1844, p. 7).

En 1845, Ricardo José Gomes Jardim, Presidente de la Provincia de Mato Grosso en la apertura de la sesión ordinária de la Asamblea Legistiva de la Provincia, el 1 de marzo de 1845, relató que la instrucción pública se encontraba en un grande atraso en la provincia mato-grossense, aunque la ley del 5 de mayo de 1837 hubiese regulado la forma de inspección en las escuelas, la habilitación, el concurso de ingreso, las preferencias, las contrataciones y los despidos de professores, la instrucción pública destinada a la educación popular era casi inexistente.

Muchas de las vacante creadas de primeras letras están vacías, $\mathrm{y}$ casi ninguna de las promovidas es frecuentada por un gran número de discípulos; lo que se explica por las diminutas órdenes marcados a los profesores, y por la falencia de las personas profesionales en las materias, que ellas deben 
enseñar, y cabe aquí hacerlos participes que las escuelas normales establecidas en esta ciudad con el propósito de enfrentar este obstáculo, habilitando el profesorado de las escuelas públicas, dejó de existir el día 9 de noviembre del año pasado, en que culminó el contrato por el respectivo docente. (GOMES JARDIM, 1845, p. 18).

Entre los años 1845 a 1869, la situación de formación de profesoras/ profesores normalistas en la Provincia mato-grossense fue poco alterada. Joaquim Raimundo de Lamare (1859) en el informe enviado a la Asamblea de la Provincia mencionó que debido a los bajos salarios pagados a los profesores solo aquellos que no consiguieran otros trabajos actuarían en el magisterio, aún así, sería una actuación ejercida por profesores sin formación adecuada.

La falta de ordenanzas que perciben los maestros, aún siendo mayores que los del año passado, continua siendo la causa principal que tenemos los indivíduos habilitados y capacitados para el magisterio. Así lo expresa el inspector general de estudios respecto al tema: aún no puedo hablar bien de estos empleados, ni de la mayoría, y a la vista de nuestro estado por falta de personal capacitado, el magisterio continua siendo entre nosotros, salvo pocas excepciones, um acopio de indivíduos que se reconocen incapaces de ganarse la vida de otro modo. (LAMARE, 1859, p. 16).

El Barón de Diamantino (1875, p. 7), Vicepresidente de la Provincia, el día 3 de mayo de 1875, en su informe presentado a la Asamblea Legislativa delineó cuánto la instrucción pública se encontraba necesitada de enormes esfuerzos y sacrificios para su desenvolvimiento en la Provincia y advirtió que no debería ser ignorado cuanto "[...] la instrucción para suavizar las costumbres y establecer en el pueblo hábitos ordenados y amor al trabajo". El Barón destaco la contribución de la Escuela Normal instalada en la Capital mato-grossense, Cuiabá, desde el día 3 de 1875 (DIAMANTINO, 1875, p. 7-8).

Escuela Normal - Se encuentra instalada en esta Capital, desde el día 3 de febrero último, la Escuela Normal creada por la Ley Provincial no 13 de 9 de julio de 1874, la cual funciona en el edificio situado en la calle Coronel Peixoto, e para este fin fue destinado. Va esta escuela produciendo ventajas que, que por el momento no compensan aún la carga de su establecimiento. Sin embargo, presagian 
lisonjeros resultados, para los cuales hay que recurrir a la poderosa excelencia de los profesores de las 4 profesiones regidas, a saber: de Gramática y análisis respectivo de la lengua nacional por Antônio Pereira Catilina da Silva, de Pedagogía y métodos por el Dr. Dormivil José dos Santos Malhado; de Matemáticas Elementares por el Contador da Tesouraria de Fazenda José Estevão Corrêa; y de Geografía e Historia por el Capitão de Artilharia reformado del Ejercito João Roberto da Cunha Bacellar.

En 1878, João José Pedrosa, destacó que la misma Escuela Normal ya citada por Diamantino en 1875, continuaba en funcionamiento. Cabe aquí resaltar que en el informe de 1878, Pedrosa describió que la Escuela Normal fue creada por la Ley Provincial no 13 . No obstante, luego destacaría que el curso normal sería compuesto por algunas clases. Nos parece que la denominación Escuela Normal fue atribuida a un conjunto de clases escolares con la finalidad de preparar profesoras/ profesores para la actuación de emergencia en la Provincia mato-grossense dado la ausencia de personas capacitadas para el ejercicio de la profesión, lo que también se muestra coherente con los extractos mencionados anteriormente.

Escuela Normal - Creada por la Ley Provincial no 14 del 9 de julio de 1874, la Escuela Normal es un establecimiento que promete mucho para el mejoramiento del magisterio. El curso se compone de las siguientes asignaturas: Geografía e Historia, Matemática, Francés, Pedagogía, Portugués. En esas disciplinas fueron matriculados 30 alumnos del sexo masculino y 5 del sexo femenino. (PEDROSA, 1878, p. 46).

El desamparo de la instrucción pública, bien como la formación improvisada de profesoras/profesores era una realidad común en Brasil. Guacira López Louro (2013, p. 448) relató que "[...] el abandono de la educación en las provincias brasileñas, denunciado desde el inicio del Imperio, se vinculaba en la opinión de muchos, la falta de maestros y maestras con buena formación. Reclamaban entonces, por las escuelas de preparación de profesores y professoras." Contribuía para eso, las insuficientes renumeraciones y muchas veces los pagos con atrasos para aquellos/aquellas que se animaban a ejercer la profesión.

No hay duda que la parcimonia de la remuneración produce el desaliento, la tibieza en el desempeño del servicio. La tarea del profesorado, sobretodo el de primaria, 
es sin duda muy noble, pero no es la menos árdua, no menos pesado, y por eso merecedora de una retribución pecuniaria que esté lo mejor posible relacionada con el trabajo que le es inherente. Sin eso, el maestro de escuela, acosado por la necesidad de buscar nuevos medios de subsistencia, además de lo que conlleva el empleo, o lo que se vive bajo la presión de la carencia de recursos pecunaiarios para acudir a las exigencias de la vida aunque sean las más modestas, descuida sus obligaciones o se torna perezoso en el cumplimiento de las mismas, teniendo como resultado, por un lado, el desprendimento progresivo de la instrucción y por otro, el desperdicio del dinero de la provincia. (BATOVY, 1884, p, 36-37).

Con todo esto, en 1889, año en el cual sería proclamada la República Brasileña, la Provincia de Mato Grosso vivía una situación de desamparo tangible cuando Antônio Herculano de Souza Bandeira, ex-director de la Instrucción Pública de la Provincia de Río de Janeiro, especialista en asuntos educativos, vino a la Provincia e implantó nueva orientación pedagógica que edificó una nueva estrutura administrativa para la enseñanza, creando órganos de dirección para organizar los organismos burocráticos de la Instrucción Pública.

Souza Bandeira (1889) reformuló los moldes que concibió el Liceo Cuiabano y de él desmembró el Liceo de Lenguas y Ciencias y el Curso Normal. El liceo de Lenguas y Ciencias pasó a tener como objetivo la formación para acceso a las escuelas superiores del país y creó para el Curso Normal el Externado del Sexo Femenino con la finalidad de preparar profesoras para la enseñanza primaria. Creó también la Directoría de la Enseñanza Primaria, extinguiendo la Directoría General de la instrucción primaria y mobilizando la preparación de las maestras con el objetivo de dirigir la enseñanza primaria (MARCílIO, 1963).

El reglamento de la Enseñanza Primaria de 1889 establecido por Souza Bandeira trató aún de las condiciones de admisión y de la provisión para el magisterio público primario e innovó que la admisión sería realizada mediante concurso público primario promovido y organizado por el Director General de la Instrucción Pública y acontecería en tres etapas: prueba escrita, oral y práctica. Además de ello, el Capítulo 3 establecería que los candidatos al magisterio público primario deberían tener una edad mayor de 18 ańos, comprobada por medio de certificado de bautismo u outra prueba jurídica; exención de delitos; moralidad, mediante certificado de autoridades civiles y ecleciásticas del lugar de residencia; robustez necesaria, probada por inspección de salud; capacidad intelectual, demostrada en concurso, en la conformidad del reglamento, salvo en 
los casos especiales en que era exonerado o liberado (MATTO GROSSO, 1889).

Para las profesoras, el Artículo 12 del Reglamento de 1889, estableció que las mujeres casadas debían presentar certificado de matrimonio, en el caso de ser viudad, el certificado de defunción del esposo e si eran divorciadas, el certificado de sentencia de separación. Nótese con esto que un determinado perfil era esperado de las profesoras.

En ese periodo, José Veríssimo, intelectual brasileño liberal y positivista, defendía que aunque fuese aceptable que las mujeres fueran escolarizadas, la educación de la mujer no debía ultrapasar los límites de la formación de la dueña de casa y madre de familia. Veríssimo celebraba una educación de la mujer integral y enciclopédica, después que no quisiese "[...] hacer de ella una sabia, ni que le exija que recorra y profundice en todos los conocimientos humanos" (VERÍSSIMO, 1985, p. 122). Para Veríssimo no sería necesario que la mujer, aún sin derechos políticos, adquiriera o que se le exigiera profundizar sus conocimientos; pues, bastaría solo que ella aprendiera lo "[...] esencial para el conocimiento del mundo y dirección de la vida” (VERÍSSIMO, 1985, p. 122).

La mujer brasileńa como la de cualquier otra sociedad de la misma civilización, tiene que ser madre, esposa, amiga y compañera del hombre, su aliada en la lucha de la vida, creadora y primera maestra de sus hijos, confidente y consejera natural de su marido, guia de su prole, dueña y reguladora de la economía de su casa, con todos los demás deberes correlativos a cada una de estas funciones. (VERÍSSIMO, 1985, p. 122).

Veríssimo (1985) alertaba aún que ese ideal de mujer tal vez no pudiese ser alcanzado, pero no por eso debería ser abandonado, pues para él todas las mujeres poseían "[...] inteligencia, que yo continúo a refutar inferior a la de los hombres [...]” lo que la convertiría incapaz (VERÍSSIMO, 1985, p. 123). A pesar de esas voces que indicaban que las mujer eran menos capaces, creadas las escuelas normales, brevemente los informes indicaban allí que más mujeres eran recibidas y formadas (LOURO, 2013).

Interesante destacar que en aquella reforma propuesta por Souza para la provisión de profesoras para las escuelas del sexo femenino, en el artículo 18, en su $2^{\circ}$ parágrafo, constaba que la mujer candidata debería ser cuestionada sobre las competencias con los “[...] trabajos de aguja y prendas domésticas".

$\$ 2^{\circ}$ - En los concursos para la provisión de escuelas de sexo femenino o escuelas de $1^{\circ}$ classe, la comisión examinadora 
escuchará las personas competentes sobre las habilitaciones de las candidatas en trabajos de aguja y prendas domésticas. (MATTO GROSSO, 1889, p. 4).

Entre los deberes de los profesores, destacamos el artículo 38 que determinaba que el professor debería cumplir una serie de determinaciones.

Artículo 38

$\$ 1$ : Presentarse puntualmente en el aula de clases, decentemente vestido, y proceder a los ejercicios escolares en los términos del reglamento interno;

$\$ 2^{\circ}$ - Mantener el orden, disciplina y regularidad en la escuela;

$\$ 3^{\circ}$ - Realizar las lecciones usando los libros y compendios adaptados y proponer al Director General la adopción de los que crean convenientes.

$\$ 4^{\circ}$ - Inspirar a los discípulos el amor al estudo y esforzarse por el progreso.

$\$ 5^{\circ}$ - Aplicar las penas disciplinares con moderación y criterio.

$\$ 6^{\circ}$ - Matricular a los alumnos, y hacer la escritura de su cargo con regularidade y anhelo.

$\$ 7^{\circ}$ - Remitir mensualmente al inspetor escolar el mapa de frecuencia de la escuela.

$\$ 8^{\circ}$ - Vigilar sobre el matenimiento y conservación del material de la escuela, siendo responsable por la desaparición o deterioro culposo.

$\$ 9^{\circ}$ - Proceder ante el inspector escolar, el inventario de los muebles y utensilios de la escuela, cuando asuma el oficio de su puesto, cuando tenga que dejarlo o cuando sea necesario, a juicio del inspector.

$\$ 10^{\circ}$ - Informar al inspector escolar cualquier impedimento que inhiba del ejercicio de sus funciones. (MATTO GROSSO, 1889, p. 7).

Era prohibido al professor residir o ausentarse de la sede de la escuela en los días lectivos sin un debido permiso, bien como ejercer alguna función incompatible con el desempeño del magisterio, además de ello, toda intermediación sobre la Instrucción Pública con el Presidente de la Provincia debía ser realizada por medio del Director General (MATO GROSSO, 1889, p. 7).

Constatamos así que la Reforma promovida por Herculano Souza Bandeira dio origen a una dinamización de la enseñanza en Mato Grosso que se encontraba 
prácticamente a la deriva. Bandeira estableció, además, el Reglamento Interno del Consejo Superior de la Instrucción Pública de la Provincia de Mato Grosso, creado por el acto de la Presidencia del 31 de marzo de 1889, a quien le competía consultas sobre las cuestiones de la Instrucción Pública, la finalidad de mejorar la legislación escolar, de emitir los resultados sobre las pruebas del concurso del magisterio de primaria y secundaria, juzgar los procesos disciplinarios y proponer medidas necesarias para promover el desenvolvimiento de la enseñanza en la Provincia y sus irregularidades. Este Consejo se organizaria en tres comissiones: pedagógica, disciplinar y administrativa.

La reforma Souza Bandeira aunque fue innovadora de convirtió en apenas un legado dado a que ocurrió en la víspera de la Proclamación de la República cuando el régimen monárquico perdía espacio. Los prometedores caminos instituidos por Herculano Souza Bandeira para la educación mato-grossense aunque no fueron sificientes para proveer los establecimientos de enseñanza que la provincia necesitaba, inspiraría los siguientes reglamentos que serían instituidos por la República.

\section{Las Escuelas Normales Colombianas}

Después de más de 10 años de guerras y disputas contra el dominio español, en el año de 1821, se reglamentó la primera Constitución Política de Colombia como República independiente y, desde entonces, se amplió el interés de los gobernantes en disminuir el analfabetismo del pueblo colombiano. Así lo manifestó el Congreso General de la República en la Ley $\mathrm{n}^{\circ} 1$ de 6 de agosto de 1821 al "[...] sentirse deseosos de promover la Instrucción Pública por ser considerada uno de los medios más poderosos para mantener la independencia y la libertad" (BOGOTÁ, 1821, p. 99).

Con la proclamación de la Ley $n^{\circ} 1$ de 6 de agosto de 1821, la Instrucción Pública en Colombia ocupó un espacio en las disposiciones legales del país, creando diversos reglamentos. Esta Ley determinó en su artículo $2^{\circ}$ el cierre de conventos que no tuvieran más de 8 religiosos para que se abrieran en las mismas instalaciones casas de escuela para la educación de los niños y las niñas. Así mismo, todos los bienes materiales que pertenecían a los conventos clausurados serían donados para las nuevas escuelas.

Uno de los aspectos a destacar de la Ley $\mathrm{n}^{\circ} 1$ de 6 de agosto de 1821 es la importancia dada a la educación de la niñas, la cual siendo "[...] una parte tan significativa y de tanto influjo en la sociedad exige poderosamente la protección del Gobierno" (BOGOTÁ, 1821, p. 102). Sin embargo, en la misma Ley se aclara 
que por causa de la guerra el gobierno no contaba con los recursos financieros para ofrecer materiales pedagógicos para las escuelas de niñas, por lo que seguiría disponiendo de los conventos como escuelas, en los cuales el poder ejecutivo sería responsable por su organización.

Las religiosas de los conventos estaban obligadas a administrar una completa educación bajo el ideal del amor a Dios y a la Patria, tal como se expone en el artículo $4^{\circ}$ de la Ley n ${ }^{\circ} 1$ del 6 de agosto de 1821.

Con conforme al breve de Su Santidad los respectivos prelados eclesiásticos harán entender a las religiosas el importante servicio que han de hacer a Dios y a la patria, dedicándose con gusto y con la actividad que debe esperarse de su amor a la virtud y al bien público, a dar una completa educación a las niñas y a las jóvenes. (BOGOTÁ, 1821, p. 103).

Además de las casas de educación, fueron creadas las escuelas de primeras letras para enseñar a leer, escribir, ortografía, principios de aritmética, religión y moral cristiana a todos los nińos y niñas que tuvieran una edad superior a seis años. En las escuelas femeninas de primeras letras, además de las disciplinas anteriores, se aprendía costura y bordado.

En la Ley $\mathrm{n}^{\circ} 1$, se reglamentó la creación de colegios en cada una de las provincias del país, en los cuales los ciudadanos eran educados para que actuar en el comercio, la agricultura, la minería, las ciencias militares y para la defensa de la República si era necesario.

Ahora bien, en lo que respecta a las escuelas normales, el artículo 15 de la Ley $\mathrm{n}^{\circ} 1$ de 1821 reglamentó la creación de estas en las principales ciudades del país, con el propósito de formar maestros capaces de enseñar los saberes básicos sobre la lectura, la escritura, la religión y la política a la nueva nación colombiana. Estos profesores debían enseñar en las escuelas distribuidas en todo el país como mecanismo para disminuir el analfabetismo de la época, para que los ciudadanos lograran ejercer el derecho al voto.

Las escuelas normales, hasta entonces sólo masculinas, debían formar maestros que difundieran en las escuelas primarias el método lancasteriano o de enseñanza mutua.

En mayo de 1822 se notificó, en la gaceta de Colombia, la fundación de la primera escuela normal del país, creada de acuerdo con la Ley de 2 de agosto de 1821, sancionada por el Congreso General, la cual abrió sus puertas en septiembre 
de 1821. La escuela normal funciona bajo la dirección del padre Fray Sebastián Mora, que implemento el método de enseñanza mutua o método lancasteriano, en honor a su fundador Joseph Lancaster. (SÁNCHEZ, 1999, p. 43).

Con la reglamentación de la Ley se creó la primera escuela normal en el país bajo la dirección de Fray Sebastián Mora, quien se dedicó a difundir el método lancasteriano o monitorial en las escuela de Colombia, con el cual se instruía al profesor para que fuera capaz de dirigir a un gran número de estudiantes, lo que le ahorraba a la nueva República recursos económicos que en la época eran escasos (PARRA, 2013) y suplía la escasez de maestros (GARCÉS, 1996). No obstante, según Osorio (2005) esta institución funcionó solo por un año.

Los conocimientos adquiridos por parte de los profesores formados en las escuelas normales lancasterianas eran casi iguales a los adquiridos por los alumnos de las escuelas primarias, lo único que los diferenciaba era el manejo del método de enseñanza, el cual era dominado por los profesores. Por tanto, las escuelas normales de la época se consideraban centros de reproducción del método de enseñanza mutua, en los cuales los profesores estaban lejos de cumplir con el ideal de educación.

Sin lugar a dudas, la escuela normal como institución para formar maestros y promover un saber sobre la enseńanza se inicia con las reformas de Ospina. En octubre de 1844 se inauguró la escuela normal del distrito de Bogotá en un edificio construido de acuerdo con las normas del método lancasteriano. El método dejó de ser el único conocimiento pedagógico de los maestros. (GARCÉS, 1996, p. 278).

Fue con la Ley de 26 de junio de 1842 que las escuelas normales adquirieron una relación directa con la formación de profesores (GARCÉS, 1996). Según Olga Zuluaga Garcés (1996) con la reforma promovida por Mariano Ospina Pérez las escuelas normales adquieren el sentido de formadoras de maestros. Su función no se limitaba a la reproducción de métodos de enseñanza, sino que se ampliaba hacia la pedagogía. Se incrementó la inspección del saber y de las habilidades del maestro para la enseńanza, creando programas de pedagogía y dándole identidad como institución al separarla de la escuela parroquial.

La primera mitad del siglo XIX no fue el periodo de mayor avance educativo para Colombia y, por consiguiente, para las escuelas normales. El país, dividido en opiniones políticas sobre cómo y quién gobernar la Nación, vivía en constantes guerras internas que afectaban directamente a la educación y al futuro de las 
escuelas formadoras de maestros, debido a que éstas sufrían las consecuencias inmediatas de los cambios políticos, económicos y administrativos. Los intereses particulares creaban conflictos que imposibilitaban la conformación de una estructura educativa sólida.

La guerra civil de 1860 a 1862 entre conservadores y liberales trajo modificaciones para el país y por ende, para su sistema educativo. Con el triunfo de los Liberales Radicales y la firma de la Constitución de 1863, la iglesia, que había ocupado un papel predominante en la educación, fue retirada del poder, al declararse la libertad religiosa como principio nacional y educativo, motivado por la valoración de las ciencias y la libertad del ciudadano (OSORIO, 2005). Por consiguiente, se reglamentó en 1870 el primer Decreto Orgánico de Instrucción Pública, y por consiguiente hubo un aumento en las disputas con relación a la educación.

La reforma educativa de 1870 representó la primera tentativa por consolidar un sistema educativo primario organizado y estructurado. Para ello, además de las leyes que regulaban la educación primaria, decretó la creación de escuelas normales en todo el país, puesto que se consideraba a los profesores como agentes esenciales en la educación escolarizada.

Si bien la escuela normal como instituto de formación de profesores intentaba en la primera mitad del siglo XIX cumplir con los objetivos planteados, es en la segunda mitad del siglo, a través del Decreto Orgánico de Instrucción Pública, que se reglamentó la fundación de la Escuela Normal Central en la ciudad de Bogotá como institución principal para instruir maestros encargados de la enseñanza en las escuelas normales de todo el país.

Se puede decir sin temor a equivocarnos que la Escuela Normal Central cumplió muy bien su papel de formadora de maestros para las demás escuelas normales del país. De diferentes partes de Colombia acudían alumnos-maestros, a realizar los curas de magisterio en la Institución y luego regresaban a sus lugares de orígenes a prestar sus servicios, pero sobretodo en las demás escuelas normales. El maestro, bien dotado de conocimiento en todo sentido, dio vida e impulso a los demás centros escolares a donde fuera a desempeñarse. (OSORIO, 2004, p. 183, 184).

En el capítulo VII del Decreto Orgánico de Instrucción Pública se disponía que en cada Estado debía existir una escuela normal encargada de formar profesores idóneos para dirigir las escuelas elementales y superiores. Uno de los avances significativos fue la ampliación de los métodos de enseñanza, la profundización 
en las áreas de conocimiento y en las disciplinas fundamentales para la enseñanza en la educación primaria así como la implementación de cursos industriales, de artes y oficios. Además, se estipuló la creación de un curso de pedagogía.

Este método pestalozziano se incorporó al sistema de educación pública con el fin de responder a las necesidades del momento y de alcanzar el progreso de la pedagogía y la educación. El decreto orgánico dejó libertad para que se introdujeran métodos nuevos y cesara el método memorístico en la enseñanza, con lo cual los dirigentes y pedagogos alemanes impulsaron nuevas teoría. (OSORIO, 2000, p. 118).

En las escuelas normales, según Osorio (2000), el método pestalozziano se fundamentaba en el desarrollo de las habilidades del estudiante a través de la búsqueda del conocimiento, en incentivar en los alumnos el deseo hacia descubrir lo desconocido. Para ello, el gobierno liberal trajo una misión alemana ${ }^{6}$ que tomó la dirección de las escuelas normales e introdujo el sistema pestalozziano a la formación de maestros.

Así, se estableció abrir una escuela normal por cada capital de Estado con el propósito de formar docentes para las escuelas elementales y superiores. Así mismo, se creó Revista Escuela Normal, órgano oficial de publicación de todos los actos del poder ejecutivo y de los asuntos relativos a la enseńanza, como lo eran los informes sobre instrucción pública de la capital y de los Departamentos del país. En total, como manifiesta Jaime Jaramillo (1980) estos fueron los dos elementos esenciales del Decreto Orgánico de Instrucción Pública de 1870.

\section{Consideraciones Finales}

A modo de conclusión, podemos afirmar que el surgimiento de las escuelas normales como instituciones formadoras de maestros para las escuelas primarias fue un fenómeno que nacido en Europa se apoderó de los países latinoamericanos. Estas escuelas tenían el propósito de formar profesores que cumplieran con los ideales del país y suplieran las necesidades educativas del pueblo.

6 La misión alemana llega a Colombia con el propósito de mejorar la calidad de la educación que se venía implementando en el país. Según María Cristina Rojas de Ferro (1982) la misión alemana ayudaría al desarrollo de programas, textos escolares, formación de profesores y el perfeccionamiento de los inspectores escolares. Ver al respecto: FERRO (1982). 
No obstante, la construcción de los fundamentos de las escuelas normales fue un proceso extenso que abarcó cambios significativos, desde su consolidación como escuelas formadoras de profesores y pasar a formar profesoras, los métodos de enseñanza, los ideales y las necesidades particulares de cada país hasta ser vistas como escuelas para suplir la demanda de profesores en un país.

Con respecto a las escuelas normales latinas, podemos afirmar que surgieron en el siglo XIX siguiendo los modelos de las escuelas normales europeas, pero pasando por procesos de transición diferenciados que respondían a una realidad particular. En el caso de las escuelas normales brasileras y colombianas, éstas nacieron para cubrir la demanda de escasez de maestros a los que se enfrentaba cada país. Así mismo, fueron creadas, primeramente, eminentemente masculinas para después convertirse en espacios femeninos.

La Escuela Normal en el estado brasileño de Mato Grosso, implementada aún en el gobierno imperial, fue marcada por la inestabilidad institucional debido a las interrupciones sucesivas, provocadas por los cambios económicos y la marcada ausencia de la inversión en la instrucción pública. Esto puede ser comprobado en los frecuentes argumentos de los presidentes de la Provincia. La Escuela Normal mato-grossense no se sostuvo por falta de incentivos y de salarios indignos a los docentes normalistas que asumían las aulas, por la inexistencia de estructuras físicas adecuadas como edificios y muebles escolares, de los materiales didácticos precarios, pero, sobretodo, debido a los limitados investimentos financieros que eran destinados a la educación en el periodo de estudio, situación que perduraría hasta después de la instalación del regimen republicano brasileño.

Las escuelas normales en Colombia tienen su historia marcada por las disputas políticas y los cambios que estas generaron. Si bien surgen desde inicios del siglo XIX, fue en la segunda mitad del siglo XIX que su auge aumentó. Ello, debido a la importancia otorgada a las escuelas normales por parte del gobierno liberal y más adelante de los gobiernos posteriores. Sin embargo, esto no la eximió de padecer dificultades severas en aspectos económicos, políticos y administrativos.

\section{Referencias}

ALLIUAUD, Andrea. Los maestros y su historia: los orígenes del magisterio argentino. Buenos Aires: Centro editor de América Latina, 1993.

BATOVY, Barão de. Relatório com que o exmo. Sr. General Barão de Batovi Presidente da Província de Matto Grosso abrio a 1a sessáo da 25a Legislatura da Respectiva Assembléa no dia 10 de outubro de 1884. Cuyabá, Typ. de J.J.R. Calháo, 1884. Disponível em: <http://brazil.crl.edu/bsd/bsd/399/000002.html>. Acesso em: 10 fev. 2017. 
BENITO, Augustín Escolano. Las escuelas normales, siglo y medio de perspectiva histórica. Revista educación, España, n. 269, p. 55-75, 1982.

BOGOTÁ. Ley 1 de 6 de Agosto de 1821. Sobre el establecimiento de escuelas de niñas en los conventos religiosos.Congreso de Colombia, 1821. Disponible en: <http://www.bdigital.unal.edu.co/21/34/leyes_de_1821.pdf>. Acceso en: 6 abr. 2015.

DIAMANTINO, Coronel Barão de. Relatório apresentado à Assembléa Legislativa de Matto-Grosso na $2^{\mathrm{a}}$ sessáo da $20^{\mathrm{a}}$ Legislatura no dia 3 de maio de 1875. Cuyabá, Typ. De Souza Neves \& C, Largo do Palácio, 1875. Disponível em: <http://brazil.crl.edu/bsd/bsd/399/000002.html>. Acesso em: 19 nov. 2017.

FERRO, María Cristina. Análisis de una experiencia: la Misión Pedagógica Alemana. Revista colombiana de educación, Bogota, n. 10, 1982.

FREIRE, Zefirino Pimentel Moreira. Falla dirigida à Assembléa Legislativa Provincial de Mato Grosso na abertura da sessáo ordinária no anno de 1844 pelo exmo. senhor presidente da província, o coronel Zefirino Pimentel Moreira Freire. Cuyabá, Typ. Provincial, 1844.

GARCÉS, Olga Zuluaga. Las Escuelas normales en Colombia (durante la reforma de Francisco de Paula Santander e Mariano Ospina Rodríguez). Revista educación y pedagogia, Medellín, n. 12/13, p. 261-278, 1996.

GOMES JARDIM, Ricardo José. Discurso recitado pelo Exmo. Presidente da Província de Matto Grosso na abertura da sessáo ordinária da Assembléa Legislativa Provincial em $1^{\circ}$ de marco de 1845. Disponível em: <http://brazil. crl.edu/bsd/bsd/399/000002.html>. Acesso em: 10 fev. 2017.

HAHNER, June Edith. A mulher brasileira e suas lutas sociais e políticas: 1850-1937. São Paulo: Editora Brasiliense, 1981.

HERNÁNDEZ, Santiago. Breve reseña histórica de la formación de los maestros de educación primaria. In: UNESCO. Proyecto principal de educación. Boletín trimestral. La Habana: v. II, n. 7, UNESCO, 1960. p. 36-48.

JARAMILlO, Jaime. Decreto Orgánico de Instrucción Pública nov. 1870. Revista colombiana de educación, Bogotá, n. 5, 1980.

LAMARE, Joaquim Raimundo de. Relatório do presidente da província de Mato Grosso para a Assembléa Legislativa Provincial em 3 de maio de 1859. Cuyabá, Typ. Cuyabana, 1859. Disponível em: <http://brazil.crl.edu/bsd/ bsd/399/000002.html>. Acesso em: 17 out. 2017. 
LOURO, Guacira Lopes. Mulheres na sala de aula. In: DEL PRIORE, Mary (Org.). História das Mulheres no Brasil. 9. ed. São Paulo: Contexto, 2013. p. $443-481$.

MATTO GROSSO. Regulamento do Ensino Primário da Província de Matto Grosso. APMT - Livro de Leis e Decretos - 1889.

MATO GROSSO. Lei Provincial n. 8 del 5 de mayo de 1837. APMT Livro de Leis e Decretos -1837.

MÚNEVAR, F. Enseñando mutuamente: una aproximación al método lancasteriano y a su apropiación en Colombia. Revista Historia de la Educación Colombiana, Pasto, v. 13, n. 13, p. 47-76, 2010.

ORTIZ, Elmer. Las primeras escuelas normales en Perú. Revista Historia de la Educación latinoamerica, Colômbia, Tunja, v. 6, p. 57-86, 2004.

OSORIO, Miryam Báez. Pedagogia pestalozziana en escuelas normales colombianas. Historia de la Educación latino-americana, Colômbia, Tunja, n. 2, 2000 .

OSORIO, Miryam Báez. El surgimiento de las escuelas normales femeninas en Colombia. Revista de educación latino-americana, Colômbia, Tunja, n. 4, 2002.

OSORIO, Miryam Báez. Las escuelas normales colombianas y la formación de maestros en el siglo XIX. EccoS, São Paulo, v. 7, n. 2, p. 427-450, jul. 2005.

OSORIO, Miryam Báez. Las escuelas normales de varones en el siglo XIX en Colombia. Historia de la Educación latino-americana, Colômbia, Tunja, v. 6, p. 179-208, 2004.

PARRA, Ana Yensy. Método lancasteriano o de enseñanza mutua en Colombia. Revista edu-física.com, Tolima, n. 11, v. 5, 2013.

PEDROSA, João José. Relatório do Presidente da Província de MattoGrosso, enviado a Assembleia no dia 1 de novembro de 1878. Cuyabá, Typ. do Liberal, 1878. Disponível em: <http://brazil.crl.edu/bsd/bsd/399/000002. html>. Acesso em: 17 out. 2017.

QUICENO, Humberto. Pedagogía católica y escuela activa en Colombia (1900-1935). Bogotá: Ediciones foro nacional por Colombia, 1988.

SCHAFFRATH, Marlete dos Anjos Silva. Escola normal: o projeto das elites brasileiras para a formação de professores. In: ENCONTRO DE PESQUISA 
INTERDISCIPLINAR EM ARTE, 1., 2008, Curitiba. Anais electrônicos... Curitiba: Universidade Estadual do Paraná, 2008, p. 142-152. Disponível em: $<$ http://www.fap.pr.gov.br/arquivos/File/Arquivos2009/Extensao/I_encontro_ inter_artes/20_Marlete_Schaffrath.pdf>. Acesso em: 2 maio 2016.

VERÍSSIMO, José. A Educaçáo Nacional. 3. ed. Porto Alegre: Mercado Aberto, 1985. 